\title{
Plasma Levels of IL-17, VEGF, and Adrenomedullin and S-Cone Dysfunction of the Retina in Children and Adolescents without Signs of Retinopathy and with Varied Duration of Diabetes
}

\author{
Kornel Semeran, ${ }^{1}$ Przemysław Pawłowski, ${ }^{2}$ Lukasz Lisowski, ${ }^{3}$ Izabela Szczepaniak, \\ Jerzy Wójtowicz, ${ }^{1}$ Sławomir Lawicki, ${ }^{4}$ Alina Bakunowicz-Lazarczyk, ${ }^{2}$ and Artur Bossowski ${ }^{1}$ \\ ${ }^{1}$ Department of Pediatrics, Endocrinology, Diabetology with Cardiology Division, Medical University of Bialystok, \\ Ulica Waszyngtona 17, 15-274 Bialystok, Poland \\ ${ }^{2}$ Department of Pediatrics Ophthalmology with Strabismus Treatment Unit, Medical University of Białystok, Ulica Waszyngtona 17, \\ 15-274 Białystok, Poland \\ ${ }^{3}$ Scientific Circle at the Department of Pediatric Ophthalmology with Strabismus Treatment Unit, Medical University of Białystok, \\ Ulica Waszyngtona 17, 15-274 Bialystok, Poland \\ ${ }^{4}$ Department of Biochemical Diagnostics, Medical University of Białystok, Ulica Waszyngtona 15A, 15-269 Białystok, Poland
}

Correspondence should be addressed to Kornel Semeran; semeran@hotmail.com

Received 12 July 2013; Revised 6 October 2013; Accepted 12 October 2013

Academic Editor: Katarzyna Zorena

Copyright (C) 2013 Kornel Semeran et al. This is an open access article distributed under the Creative Commons Attribution License, which permits unrestricted use, distribution, and reproduction in any medium, provided the original work is properly cited.

\begin{abstract}
The study objective was to assess chosen biochemical parameters of blood and bioelectric function of the retina in patients with T1DM. The study group consisted of 41 patients with T1DM with no signs of diabetic retinopathy. The control group included 21 pediatric patients. We performed (1) S-cone ERG testing with retina response stimulation in both eyes at the luminance of 0.1, 0.2, and $0.5\left(\mathrm{~cd} \times \mathrm{s} / \mathrm{m}^{2}\right)$ with the $440 \mathrm{~nm}$ blue flash and light application of the amber background $\left(300 \mathrm{ph} \mathrm{cd} / \mathrm{m}^{2}, 495 \mathrm{~nm}\right.$ wavelength), (2) anthropometric measurements, (3) biochemical investigations: IL-17, VEGF, and ADM by the ELISA method. A comparison of the ERG results with biochemical investigations indicates a likely correlation between the worsening of retinal bioelectric function and VEGF levels growing with diabetes duration. We showed a negative correlation between ADM and HbAlc and described possible causes of ADM reduction observed in subgroup I. We demonstrated the presence of bioelectric retinal dysfunction already before the diagnosis of diabetic retinopathy, which provides new possibilities in the diagnosis of preclinical chronic complications of diabetes. The changes observed in the levels of IL-17, ADM, and VEGF suggest their involvement in the diabetic pathogenesis of eye diseases.
\end{abstract}

\section{Introduction}

Due to the systemic character of diabetes, virtually any organ can become damaged. The vision system is one of the first body parts exhibiting microcomplications and dysfunction, which is an important issue in modern diabetology [1].

Over $90 \%$ of patients with type 1 diabetes (TIDM) of 15 years' and longer duration show features of retinopathy, whereas in type 2 diabetes (T2DM) approximately $5 \%$ are affected at the time of diagnosis $[1,2]$.

The scale of the problem is extremely large, as among the 2.5 million of the Polish diabetic population, the number of cases with diabetic retinopathy is estimated at 600,000 [3]. Thanks to the dynamic progress in the development of diagnostic methods and the use of modern appliances, diabetes is known to affect all the anatomical structures of the eyeball [4].

Apart from vascular changes, diabetes may also cause neurophysiological lesions $[5,6]$. Functional changes of retinal neurons are detected by electro physiological tests, being a noninvasive and highly objectivediagnostic tool. Quick detection of retinopathy and immediate implementation of appropriate treatment reduce individual and social expenses and improve life quality [7-9]. 
TABLE 1: General profile of the study groups.

\begin{tabular}{|c|c|c|c|c|}
\hline & Patients with diabetes $>10$ years & Patients with diabetes $\leq 10$ years & Whole study group & Control group \\
\hline Number of patients & 22 & 19 & 41 & 21 \\
\hline Age (years) & $16.0 \pm 1.0$ & $13.0 \pm 3.0^{* *}$ & $14.0 \pm 3.0$ & $15.0 \pm 2.0$ \\
\hline $\operatorname{BMI}\left(\mathrm{kg} / \mathrm{m}^{2}\right)$ & $23.0 \pm 4.0^{*}$ & $20.0 \pm 5.0$ & $21.0 \pm 4.0$ & $20.0 \pm 3.0$ \\
\hline Mean HbAlc (\%) & $9.4 \pm 1.6^{*}$ & $9.3 \pm 1.7^{* *}$ & $9.3 \pm 1.7^{* * *}$ & $5.5 \pm 0.3$ \\
\hline Total cholesterol (mg/dL) & $169.0 \pm 24.0$ & $181.0 \pm 47.0$ & $175.0 \pm 37.0$ & $158.0 \pm 18.0$ \\
\hline LDL-cholesterol (mg/dL) & $93.0 \pm 24.0$ & $97.0 \pm 34.0$ & $95.0 \pm 29.0$ & $84.0 \pm 16.0$ \\
\hline HDL-cholesterol (mg/dL) & $60.0 \pm 14.0$ & $65.0 \pm 17.0$ & $63.0 \pm 16.0$ & $59.0 \pm 11.0$ \\
\hline Triacylglycerol (mg/dL) & $78.0 \pm 22.0$ & $92.0 \pm 69.0$ & $85.0 \pm 51.0$ & $74.0 \pm 35.0$ \\
\hline Systolic RR (mmHg) & $113.0 \pm 8.0$ & $114.0 \pm 10.0$ & $114.0 \pm 9.0$ & $110.0 \pm 11.0$ \\
\hline Diastolic RR (mmHg) & $69.0 \pm 5.0$ & $69.0 \pm 6.0$ & $69.0 \pm 6.0$ & $69.0 \pm 11.0$ \\
\hline IL-17 (pg/mL) & $18.0 \pm 4.0$ & $16.0 \pm 2.0$ & $17.0 \pm 3.0$ & $16.0 \pm 2.0$ \\
\hline $\mathrm{ADM}(\mathrm{pg} / \mathrm{mL})$ & $39.0 \pm 23.0$ & $27.0 \pm 22.0^{* *}$ & $36.0 \pm 27.0^{* * *}$ & $58.0 \pm 32.0$ \\
\hline VEGF (pg/mL) & $342.0 \pm 278.0$ & $379.0 \pm 200.0$ & $362.0 \pm 237.0$ & $273.0 \pm 142.0$ \\
\hline
\end{tabular}

Data are presented as mean \pm SD.

${ }^{*} P<0.05$ as compared to control group (Student's $t$-test).

${ }^{* *} P<0.05$ as compared to control group (Student's $t$-test).

${ }^{* * *} P<0.05$ as compared to control group (Student's $t$-test).

While preparing the project, we were aware of the necessity to distinguish risk groups at an early stage undetectable by standard methods. Color vision disorders experienced by diabetic patients were already described in the 1980s [10] and as shown by the study [11], they have been found to affect $8.6 \%$ of diabetic patients [12].

Disorders have been noted in the formation and transmission of S-cone signals, which may be associated with their high sensitivity to hypoxia [12]. The dysfunction of the OPs on the ascending arm of the b-wave in full-field ERG responses has been emphasized. A relationship has been revealed between the reduction in the amplitude of the OPs and longlasting diabetic retinopathy, especially the proliferative one $[13,14]$. However, very few studies have been concerned with functional alterations developing at an early stage, when no lesions can be seen in the fundus of the eye.

The study objective was to find out, using the S-cone ERG protocol, whether juvenile patients with TIDM, with no visible lesions in the fundus of the eye, and with normal optic disc morphology reveal retinal dysfunction. We also wanted to determine if the disease duration and metabolic control affect neurophysiological conduction in the outer layers of the retina.

In addition, we analyzed the concentration levels of $\mathrm{ADM}$ as a protective factor, VEGF as a known marker of hypoxia, and IL-17.

Reports in recent years have mainly concentrated on IL17 , emphasizing its proinflammatory nature and involvement of Th17 cells that produce it in the pathogenesis of diabetes and other endocrinopathies and allergic diseases. Apart from diabetes, elevated levels of IL-17 in the serum and affected tissues have been reported by patients with rheumatoid arthritis, psoriasis, multiple sclerosis, and systemic lupus erythematosus. Its proangiogenic activity is known from research on cancer immunology $[15,16]$.

\section{Material and Methods}

The study group consisted of 41 patients with T1DM. Two subgroups were distinguished as follows:

subgroup I: 22 patients with diabetes of $\geq 5 \leq 10$ years' duration.

subgroup II: 19 patients with diabetes lasting longer than 10 years.

The control group included 21 pediatric patients. Table 1 presents the group profile.

The inclusion criteria for the diabetic group were age 8-18 years, normal routine eye test results (best corrected visual acuity, color vision, slit lamp examination, and fundus examination), and negative history of the present illness that might affect the function of the retina and optic nerve. The exclusion criteria included patients with chronic diseases, eye disorders that might affect the retinal function and optic nerve, and electrophysiological testing. The inclusion criteria for the control group were age 8-18 years, normal routine eye test result, and negative history of the present illness known to affect the function of the retina and optic nerve.

Thirty-two patients with T1DM (including 19 from subgroup I, 13 from subgroup II) and 8 from the control group underwent the following. (1) First is light adapted blue flash (440 nm wavelength) ERG with increasing flash intensity 0.1, 0.2 , and $0.5\left(\mathrm{~cd} \times \mathrm{s} / \mathrm{m}^{2}\right)$ on the constant amber background (300 ph cd $/ \mathrm{m}^{2}, 494 \mathrm{~nm}$ wavelength). The stimulus duration was $4 \mathrm{~ms}$ and 10 responses were averaged and repeated twice. The ERGs were recorded simultaneously from both eyes with the use of DTL electrodes placed in the lower fornix. The pupils were dilated and subjects were light-adapted for $10 \mathrm{~min}$. All ERG tests were performed on Espion $\mathrm{E}^{2}$ system (Diagnosys, LLC, USA). They also underwent (2) biochemical investigations: HbAlc, lipid profile, IL-17, VEGF, and ADM, using the immunoenzymatic ELISA method 
TABLE 2: Comparison of b-wave amplitudes in S-cone ERG of the eyes of patients in all study groups.

\begin{tabular}{lccc}
\hline Patients with diabetes $>10$ years & Patients with diabetes $\leq 10$ years & Whole study group & Control group \\
\hline & b-wave amplitude $(\mu \mathrm{V})$ for the $0.2 \mathrm{~cd} \times \mathrm{s} / \mathrm{m}^{2}$ stimulus & $9.0 \pm 6.0^{*}$ & $13.0 \pm 5.0$ \\
$10.0 \pm 5.0$ & $8.0 \pm 6.0^{*}$ & $18.0 \pm 8.0^{*}$ & $24.0 \pm 10.0$ \\
\hline & b-wave amplitude $(\mu \mathrm{V})$ for the $0.5 \mathrm{~cd} \times \mathrm{s} / \mathrm{m}^{2}$ stimulus & $17.0 \pm 8.0^{*}$ & $18.0 \pm 8.0^{*}$ \\
\hline
\end{tabular}

Data are presented as mean \pm SD.

${ }^{*} P<0.05$ as compared to control group.

(R\&D and EiAAb kits). Laboratory tests were performed in the Department of Laboratory Diagnostics, Children's University Hospital in Białystok, during routine diagnostic procedures and in the laboratory at the Department of Pediatrics, Endocrinology, Diabetology with Cardiology Division, Children's University Hospital.

The study was approved by the Bioethics Committee, Medical University of Białystok. Parents and children were informed about the purpose and nature of the study. The parents gave a written consent, whereas the children expressed a spoken consent before examination.

\section{Statistical Analysis}

The statistical analysis was performed using the Statistica 10.0 software (Cracow, StatSoft). Deviation from normality was evaluated by Kolmogorov-Smirnov test. Data were expressed as the mean value $\pm \mathrm{SD}$. We used paired samples $t$-test for the continuous variables with normal distribution. The Wilcoxon test was employed for the continuous variables outside the normal distribution. Multiple linear regression and Spearman correlation analyses were used to verify the correlation. All probability values were two-tailed, and a value of $P<0.05$ was considered statistically significant.

\section{Results}

4.1. Electrophysiological Tests. All patients included in the study had full far and near visual acuity and clear ocular media.

A comparison of the mean values in the study group (all diabetic patients) and control showed a statistically significant reduction in the amplitude of the S-cone ERG bwave in the group of 64 eyes for the $0.2 \mathrm{~cd} \times \mathrm{s} / \mathrm{m}^{2}(9.0 \pm 6.0 \mu \mathrm{V}$ versus $13.0 \pm 5.0 \mu \mathrm{V} ; P=0.01)$ stimulus and for the $0.5 \mathrm{~cd} \times$ $\mathrm{s} / \mathrm{m}^{2}(18.0 \pm 8.0 \mu \mathrm{V}$ versus $24.0 \pm 10.0 \mu \mathrm{V} ; P=0.0084)$ stimulus. No significant deviations were noted in the wave amplitude or latency prolongation for the S-cone ERG a-wave and b-wave.

In subgroup I (38 eyes), a statistically significant decrease was observed in the amplitude of the $S$-cone ERG b-wave for $0.2 \mathrm{~cd} \times \mathrm{s} / \mathrm{m}^{2}(8.0 \pm 6.0 \mu \mathrm{V}$ versus $13.0 \pm 5.0 \mu \mathrm{V} ; P=0.0065)$ and $0.5 \mathrm{~cd} \times \mathrm{s} / \mathrm{m}^{2}(17.0 \pm 8.0 \mu \mathrm{V}$ versus $24.0 \pm 10.0 \mu \mathrm{V} ; P=$ $0.010)$.

I n subgroup II (26 eyes), a significant drop in the b-wave amplitude was found only for the $0.5 \mathrm{~cd} \times \mathrm{s} / \mathrm{m}^{2}$ stimulus as compared to the control group $(18.0 \pm 8.0 \mu \mathrm{V}$ versus $24.0 \pm$ $10.0 \mu \mathrm{V} ; P=0.048)$.

A comparison between subgroup I and subgroup II did not show any significant effect of diabetes duration on the amplitude and latency of the S-cone ERG a- and b-waves. Table 2 presents statistically significant results.

4.2. Biochemical and Biometric Investigations. All diabetic patients had higher levels of TCh, LDL, TG, and IL-17 as compared to healthy subjects, that is $(175.0 \pm 37.0 \mathrm{mg} / \mathrm{dL}$ versus $158.0 \pm 18.0 \mathrm{mg} / \mathrm{dL} ; P=\mathrm{ns})(95.0 \pm 29.0 \mathrm{mg} / \mathrm{dL}$ versus $84.0 \pm 16.0 \mathrm{mg} / \mathrm{dL} ; P=\mathrm{ns})(85.0 \pm 51.0$ versus $74.0 \pm$ $35.0 \mathrm{mg} / \mathrm{dL} ; P=\mathrm{ns})(17.0 \pm 3.0 \mathrm{pg} / \mathrm{mL}$ versus $16.0 \pm 2.0 \mathrm{pg} / \mathrm{mL}$; $P=\mathrm{ns})$, respectively. They also showed higher levels of SBP $(114.0 \pm 9.0 \mathrm{mmHg}$ versus $110.0 \pm 11.0 \mathrm{mmHg} ; P=\mathrm{ns})$ as compared to healthy children. The mean level of VEGF was significantly higher in diabetic patients, yet without statistical significance $(362.0 \pm 237.0$ versus $273.0 \pm 142.0 \mathrm{pg} / \mathrm{mL} ; P=$ ns). A statistically significant finding was that ADM level in this group was lower than in the control $(36.0 \pm 27.0$ versus $58.0 \pm 32.0 \mathrm{pg} / \mathrm{mL} ; P<0.05)$.

A comparison between subgroup I and control revealed significantly lower ADM values $(27.0 \pm 22.0$ versus $53.0 \pm$ $29.0 \mathrm{pg} / \mathrm{mL} ; P<0.05)$. We observed higher levels of TCh, $\mathrm{LDL}$, and TG $(181.0 \pm 47.0$ versus $158.0 \pm 18.0 \mathrm{mg} / \mathrm{dL}$; $P=\mathrm{ns})(97.0 \pm 34.0$ versus $84.0 \pm 16.0 \mathrm{mg} / \mathrm{dL} ; P=\mathrm{ns})$ $(92.0 \pm 69.0$ versus $74.0 \pm 35.0 \mathrm{mg} / \mathrm{dL} ; P=\mathrm{ns})$, respectively. The values of SBP were increased as compared to healthy subjects $(114.0 \pm 10.0$ versus $110.0 \pm 11.0 \mathrm{mmHg} ; P=\mathrm{ns})$. VEGF was considerably higher in the subgroup patients, yet without statistical significance $(379.0 \pm 200.0$ versus $273.0 \pm$ $142.0 \mathrm{pg} / \mathrm{mL} ; P=\mathrm{ns})$. The concentrations of IL-17 were similar $(16.0 \pm 2.0$ versus $16.0 \pm 2.0 \mathrm{pg} / \mathrm{mL} ; P=\mathrm{ns})$.

A comparison between subgroup II and control showed significantly higher BMI values in diabetic patients $(23.0 \pm$ 4.0 versus $20.0 \pm 3.0 ; P<0.05$ ). Previously, we noted unfavorable differences in lipid metabolism for TCh, LDL, and TG $(169.0 \pm 24.0$ versus $158.0 \pm 18.0 \mathrm{mg} / \mathrm{dL} ; P=\mathrm{ns})$ $(93.0 \pm 24.0$ versus $84.0 \pm 16.0 \mathrm{mg} / \mathrm{dL} ; P=\mathrm{ns})(78.0 \pm 22.0$ versus $74.0 \pm 35.0 \mathrm{mg} / \mathrm{dL} ; P=\mathrm{ns})$. Also in this subgroup, $\mathrm{ADM}$ appeared lower than in healthy subjects $(39.0 \pm 23.0$ versus $58.0 \pm 32.0 \mathrm{pg} / \mathrm{mL} ; P=\mathrm{ns}$ ). A tendency of higher IL-17 and VEGF levels was confirmed in diabetic patients as compared to the control group $(18.0 \pm 4.0$ versus $16.0 \pm 2.0$ $\mathrm{pg} / \mathrm{mL} ; P=\mathrm{ns})(342.0 \pm 278.0$ versus $273.0 \pm 142.0 \mathrm{pg} / \mathrm{mL}$; $P=\mathrm{ns})$. 
TABLE 3: Multiple linear regression analyses for b-wave amplitudes for $0.2 \mathrm{~cd} \times \mathrm{s} / \mathrm{m}^{2}$, b-wave amplitudes for $0.5 \mathrm{~cd} \times \mathrm{s} / \mathrm{m}^{2}$, and b-wave implicit time for $0.5 \mathrm{~cd} \times \mathrm{s} / \mathrm{m}^{2}$ as dependent variables.

\begin{tabular}{|c|c|c|c|c|c|c|c|}
\hline \multirow{2}{*}{ Dependent variable } & \multirow{2}{*}{$r^{2}$} & \multirow{2}{*}{ Independent variable } & \multicolumn{2}{|c|}{ Unstandardized coefficients } & \multirow{2}{*}{ Standardized coefficients $\beta$} & \multirow{2}{*}{$t$} & \multirow{2}{*}{$P$} \\
\hline & & & $B$ & Standard $B$ error & & & \\
\hline \multirow{3}{*}{$\begin{array}{l}\text { b-wave amplitude } \\
0.2 \mathrm{~cd} \times \mathrm{s} / \mathrm{m}^{2}\end{array}$} & \multirow{3}{*}{0.38} & Constant & 14.69 & 7.24 & & 2.03 & 0.0469 \\
\hline & & VEGF & 1.10 & 0,25 & -0.25 & -2.13 & 0.0376 \\
\hline & & LDL-cholesterol & -0.13 & 0.03 & -0.45 & -4.03 & 0.0001 \\
\hline \multirow{3}{*}{$\begin{array}{l}\text { b-wave amplitude } \\
0.5 \mathrm{~cd} \times \mathrm{s} / \mathrm{m}^{2}\end{array}$} & \multirow{3}{*}{0.43} & Constant & -0.2 & 7.72 & & -0.03 & 0.9799 \\
\hline & & HbAlc & -1.81 & 0.57 & -0.42 & -3.19 & 0.0022 \\
\hline & & LDL-cholesterol & -0.35 & 0.08 & -0.84 & -4.53 & 0.0004 \\
\hline \multirow{3}{*}{$\begin{array}{l}\text { b-wave implicit time } \\
\text { for } 0.5 \mathrm{~cd} \times \mathrm{s} / \mathrm{m}^{2}\end{array}$} & \multirow{3}{*}{0.31} & Constant & 46.40 & 1.55 & & 30.02 & 0.0000 \\
\hline & & HDL-cholesterol & -0.01 & 0.01 & -0.25 & -2.21 & 0.0307 \\
\hline & & IL-17 & 0.22 & 0.08 & 0.33 & 2.75 & 0.0079 \\
\hline
\end{tabular}

In multiple regression analysis, b-wave amplitude for the impulse $0.2 \mathrm{~cd} \times \mathrm{s} / \mathrm{m}^{2}$ demonstrated a significant inverse relationship with VEGF $\left(r^{2}=0.38\right.$, coefficient $\beta=-0.25$, $P<0.04)$ and LDL $\left(r^{2}=0.38\right.$, coefficient $\beta=-0.45$, $P<0.00002$ ).

In multiple regression analysis, b-wave amplitude for the impulse $0.5 \mathrm{~cd} \times \mathrm{s} / \mathrm{m}^{2}$ yielded significant inverse findings with HbAlc $\left(r^{2}=0.43\right.$, coefficient $\left.\beta=-0.42, P<0.003\right)$ and LDL $\left(r^{2}=0.43\right.$, coefficient $\left.\beta=-0.84, P<0.00004\right)$. In multiple regression analysis, $\mathrm{b}$-wave implicit time for $0.5 \mathrm{~cd} \times$ $\mathrm{s} / \mathrm{m}^{2}$ demonstrated significant inverse relationship with HDL $\left(r^{2}=0.31\right.$, coefficient $\left.\beta=-0.25, P<0.04\right)$ and positive relationship with IL-17 $\left(r^{2}=0.31\right.$, coefficient $\beta=0.33$, $P<0.008)$. Data are presented in Table 3 .

\section{Discussion}

Numerous studies have confirmed the correlation between metabolic control and the incidence of diabetes-associated visual complications. Among them, Wisconsin Epidemiology Study, Berlin Retinopathy Study, the Early Treatment Diabetic Retinopathy Study, and the United Kingdom Prospective Diabetes Study have focused on the natural course of diabetic retinopathy [11, 17-19]. In 2003, Younis et al. investigated the annual and overall prevalence of any sign of diabetic retinopathy, maculopathy, and vision-threatening diabetic retinopathy in patients with T1DM and T2DM, who underwent screening tests [20]. There is evidence that visionthreatening diabetic retinopathy has a detectable occult stage or an early symptomatic phase.

The collected scientific data suggest that neurophysiological alterations in the retina are already present in the initial stages of diabetes $[6,21]$.

We confirmed the impact of the disease and poor metabolic control measured by the percentage of HbAlc on the responses obtained from the S-cone ERG prior to clinical symptoms of retinopathy. Diabetic children were found to show a significant reduction in the S-cone ERG b-wave amplitude with stimuli $\geq 0.2 \mathrm{~cd} \times \mathrm{s} / \mathrm{m}^{2}$, as compared to healthy subjects.
Previously, it was indicated that the alterations in the electric activity of the middle layers of the retina, that is, in bipolar cells, horizontal cells, and Muller's cells, were present in the course of diabetes $[13,21]$. The S-cone ERG applied in our study shows the activity of the S-cones (blue-sensitive), which are characterized by the maximum sensitivity to the short-wavelength part of the light spectrum and account only for $10 \%$ of the whole population of cones and less than $1 \%$ of the entire population of all retinal receptors [13]. Data are available indicating selective damage to the transduction pathway that begins in the S-cone and leads to discrete disturbances in color recognition, called tritanopia, which has not been fully explained yet. It seems that the Scones are particularly sensitive to hypoxia involved in the pathophysiology of diabetes-associated alternations. Apart from the impaired metabolism of retinal neurotransmitters, scientists also point at the role of enhanced premature apoptosis or defective tightness in the blood-retinal barrier. Plasma protein migration accompanying this disorder may have an impact on the degree of absorption and/or light dispersion, causing a reduction in light reception by cones. Moreover, some of these proteins, including the non-enzymatic glycosylated ones, absorb ultraviolet light [4, 6, 22-25].

The ERG findings are similar to those reported by McFarlane et al. [6] in the assessment of the b-wave amplitude. In contrast to the above, we found no a- wave or b-wave delay. However, even the reduction of photopic negative response of S-cone amplitude itself suggests functional alterations in the inner layers of the retina that attenuates the quality of the S-cone impulse.

The multivariate regression analysis shows a negative correlation between $\mathrm{HbAlc}$ and the height of b-wave amplitude, which is observed for the most intense light pulse $(0.5 \mathrm{~cd} \times$ $\mathrm{s} / \mathrm{m}^{2}$ ). As indicated in Table 2 , the b-wave amplitude values for the stimulus differ significantly in both groups of diabetic children in comparison with the control group. This suggests that the highest diagnostic value, in the search for early functional changes in the retina, pulses with intensity of at least $0.5 \mathrm{~cd} \times \mathrm{s} / \mathrm{m}^{2}$.

Our results are consistent with the data reported by authors who have assessed bioelectric activities of the retina 
by means of other electrophysiological methods [26-31]. A direct comparison of the results is difficult due to the use of different equipment, protocols, and group sizes. However, the common conclusion that can be drawn from these studies is that the objective neurotransmission disorders can appear in diabetic patients who still have normal eye fundus.

A number of growth factors responsible for diabetic retinopathy have been described. They are known to be involved both in the initial and proliferative phases of the process. However, no major factor has been found responsible for the stimulation of neovascularization in diabetic eye disease. The current study indicates the key role of VEGF, whose increase is one of the exponents of endothelial dysfunction, leading to increased permeability of the bloodtissue barrier; hence, its former name is vascular permeability factor [32-34]. The regulation of VEGF gene expression is stimulated mainly by hypoxia $[35,36]$. High level of VEGF has been noted in the vitreous humor in retinopathy patients and in many eye disorders presenting with local hypoxia and neovascularization [37-39]. We found a tendency to higher serum levels of VEGF in diabetic patients as compared to the control, irrespective of diabetes duration. It can be assumed that the increased level of VEGF reflects endothelial dysfunction which appears earlier than the structural changes observed by ophthalmoscopy within the vascular walls. Taking into consideration the data reported by Santilli et al., this hypothesis can be referred to as a broader aspect of diabetic complications [40]. This author performed a prospective observation, showing a correlation between serum VEGF and the risk of nephropathy in diabetic patients. He proved that the maintenance of the increased serum level of VEGF facilitates the identification of patients with normal arterial blood pressure and normoalbuminuria, who are predisposed to the development of permanent microalbuminuria later in life.

An interesting hypothesis can be derived from reports on the significant increase in VEGF in the immunocytochemical analysis of nonvascular eye cells in diabetic patients, even, like in our study, with no signs of retinopathy [41, 42]. Considering the bioelectric disorders in the S-cone ERG, this would suggest that retinopathy originates in retinal neurons and glial tissue and only later affects blood vessels.

Our observations in the context of the data already collected on VEGF allow a wider perspective as to the role of this protein in the pathogenesis of visual complications of diabetes. Further studies are necessary to precisely determine the mechanisms linking VEGF to retinopathy.

In the last years, ADM has been found to have a potentially beneficial effect on the hemodynamics and neurohormonal regulation of the circulatory system. This protein has been detected not only in the cells of the adrenal medulla, but also in other tissues including smooth muscle cells, vascular endothelium cells, and retinal pigment epithelial cells. The collected data indicate a link between ADM and pathophysiological processes in diabetes accompanied by elevated levels of ADM, especially in advanced complications [43-45]. On the other hand, increased ADM can be associated with reduced renal clearance of this protein in the development of nephropathy, even though it is metabolized in the pulmonary circulation $[46,47]$. This peptide is thought to be engaged in antiregulatory mechanisms, by preventing vasoconstriction, increasing natriuresis, and inhibiting platelet aggregation. Hence, the hypothesis that the level of ADM reflects endothelial activation is additionally supported by a positive correlation observed between CAMP and ADM, a second line transmitter involved in the regulation of the circulatory system $[48,49]$.

In 1999, that is, 6 years after ADM identification, Taniguchi et al. [50] were the first to present the effect of $\mathrm{ADM}$ on the eye, especially ciliary body and cornea, and thus on the regulation of intraocular pressure. Pigment epithelial cells also produce and secrete ADM, which stimulates back the proliferation of these cells. Udono et al. [45] claimed that levels of ADM in the vitreous humor of patients with vitreoretinal proliferations were significantly higher in patients with proliferative diabetic retinopathy. A few years later, the same author proved in vitro that hypoxia increases ADM expression in the human pigment epithelial cell line and that the use of exogenous ADM increases survival of the cell line exposed to hypoxia [51], thus confirming a beneficial effect of this protein on retinal metabolism. The data suggest that ADM may be involved in the pathogenesis of diabetic retinopathy, especially that retinal arteries have been recognized as its uptake point [52]. Thus, our observation of decreased serum ADM in children with diabetes of less than 10 years' duration, especially in the context of a weaker response in the S-cone ERG and higher serum levels of VEGF, lipids, and higher blood pressure, seems surprising, even though a substantial increase in the level of ADM has been demonstrated only in patients burdened with overt retinopathy, microalbuminuria, or renal failure [48]. Our study, however, does not exclude a local increase in the level of ADM, for example, in eye tissues, before its rise in the serum; in patients with diabetes $>10$ years' duration, the level of ADM is already higher. Taking into account the negative correlation between $\mathrm{ADM}$ and $\mathrm{HbAlc}$ in the $\leq 10$ years' subgroup, this is presumably caused by the protein consumption in unfavorable conditions of hyperglycemia. An alternative hypothesis suggests that increased ADM in diabetes is a late effect associated with progressing vascular endothelial dysfunction. It should be emphasized that our study group consisted of children, mainly adolescents, who were in the period of intensive hormonal changes, which undoubtedly affected the circulatory system.

The fact is that the level of ADM in diabetes undergoes changes even in the pediatric population and that their direction and significance require further investigations.

Still very few studies, mainly performed on the animal models of autoimmune diabetes, indicate a disorder in IL17, which can have a significant impact on the course of the disease. Also, clinical studies based on human material indicate a serious disturbance in the cell population in T1DM. The few available studies concerning children with T1DM have shown an increased secretion of IL-17 [53, 54].

Therefore, in further elucidation of the importance of Th17 and IL-17 cells in T1DM, interesting may seem the studies that evaluate the role of IL-17 from an early clinical stage to a later period (after the end of remission) and thus 
assess the importance of the initiation and modulation of the inflammatory response and in consequence the effect on the disease and disclosure of complications [55]. It is believed that IL-17 may play a major role in the cytokine network regulating immune responses, inflammatory responses, or angiogenesis. It is possible that IL-17 is indirectly involved in these reactions through the effect on the expression of other more targeted cytokines. Research of Numasaki et al. [16] has shown that IL-17 is an angiogenesis mediator, acting directly on endothelial cells and through other lymphokines with angiogenic properties. This can be confirmed by the common direction of changes obtained in our study in the levels of IL-17 and VEGF.

Since IL-17 is involved in the pathogenesis of many diseases described above and their complications, its regulation provides new diagnostic, prognostic, and therapeutic potentials.

\section{Conclusion}

Since we found that the S-cone visual pathway is affected in adolescent patients with type 1 diabetes and without evidence of retinopathy, the S-cone ERG test may be a useful marker of early stage of inner retinal damage. Our results indicate that the short-wavelength abnormalities detected in T1DM before the onset of retinopathy originate in the retina.

The changes observed in the levels of ADM, IL-17, and VEGF support their possible involvement in the microvascular complications of diabetes. Different than expected results in $\mathrm{ADM}$ concentration in group I indicate that further in vivo studies are needed to clarify the role of ADM in this process.

We believe that our findings may help elucidate the mechanisms of retinopathy in order to protect the eyesight in young diabetic patients.

\section{Abbreviations}

ADM: Adrenomedullin

BMI: Body mass index

cAMP: Cyclic adenosine monophosphate

ERG: Electroretinogram

HDL: HDL-cholesterol

IL-17: Interleukin-17

LDL: LDL-cholesterol

OPs: Oscillatory potentials

SBP: $\quad$ Systolic blood pressure

S-cone: Short-wavelength cone

T1DM: Type 1 diabetes mellitus

T2DM: Type 2 diabetes mellitus

TCh: Total cholesterol

TG: Triacylglycerol

Th17: T-helper 17 cells

VEGF: Vascular endothelial growth factor.

\section{References}

[1] H. King, R. E. Aubert, and W. H. Herman, "Global burden of diabetes, 1995-2025: prevalence, numerical estimates, and projections," Diabetes Care, vol. 21, no. 9, pp. 1414-1431, 1998.
[2] B. Mirkiewicz-Sieradzka, "Progress in diagnosis and treatment of diabetic retinopathy," Diabetologia Praktyczna, vol. 7, no. 1, pp. 30-36, 2006.

[3] "Cukrzyca ukryta pandemia-sytuacja w Polsce," Tech. Rep., Novo Nordisk, Warsaw, Poland, 2011.

[4] E. Spoz, W. Lubiński, and D. Karczewicz, "The pattern electroretinogram test in patients with diabetes mellitus type 1 with normal fundus," Annales Academiae Medicae Stetinensis, vol. 53, supplement 1, pp. 35-42, 2007.

[5] A. J. Barber, "A new view of diabetic retinopathy: a neurodegenerative disease of the eye," Progress in NeuroPsychopharmacology and Biological Psychiatry, vol. 27, no. 2, pp. 283-290, 2003.

[6] M. McFarlane, T. Wright, D. Stephens, J. Nilsson, and C. A. Westall, "Blue flash ERG PhNR changes associated with poor long-term glycemic control in adolescents with type 1 diabetes," Investigative Ophthalmology \& Visual Science, vol. 53, no. 2, pp. 741-748, 2012.

[7] H. Sakai, Y. Tani, E. Shirasawa, Y. Shirao, and K. Kawasaki, "Development of electroretinographic alterations in streptozotocininduced diabetes in rats," Ophthalmic Research, vol. 27, no. 1, pp. 57-63, 1995.

[8] W. Liu and Y. Deng, "The analysis of electroretinography of diabetes mellitus," Yan Ke Xue Bao, vol. 17, no. 3, pp. 173-179, 2001.

[9] M. Vadalà, M. Anastasi, G. Lodato, and S. Cillino, "Electroretinographic oscillatory potentials in insulin-dependent diabetes patients: a long-term follow-up," Acta Ophthalmologica Scandinavica, vol. 80, no. 3, pp. 305-309, 2002.

[10] M. L. Daley, R. C. Watzke, and M. C. Riddle, "Early loss of bluesensitive color vision in patients with type I diabetes," Diabetes Care, vol. 10, no. 6, pp. 777-781, 1987.

[11] R. Klein, B. E. Klein, S. E. Moss, M. D. Davis, and D. L. DeMets, "The Wisconsin epidemiologic study of diabetic retinopathy. IV. Diabetic macular edema," Ophthalmology, vol. 91, no. 12, pp. 1464-1474, 1984.

[12] B. Mirkiewicz-Sieradzka, H. Zygulska-Machowa, and B. Romanowska, "Evaluation of macular function in patients with diabetic retinopathy," Klinika Oczna, vol. 88, no. 6, pp. 209-211, 1986.

[13] O. Palacz, W. Lubioski, and K. Penkala, Electrophysiological Diagnosis of the Visual System, Oftal, Warsaw, Poland, 1st edition, 2003.

[14] E. Langwińska-Wośko, "Effect of diabetes type I duration on changes of oscillatory potentials in ERG of children and youth," Klinika Oczna, vol. 95, no. 6, pp. 230-232, 1993.

[15] A. Bossowski, M. Moniuszko, E. Idzkowska et al., "Evaluation of CD4+CD161+CD196+ and CD4+IL-17+ Th17 cells intheperipheral blood of young patients with Hashimoto's thyroiditis and Graves' disease," Pediatric Endocrinology, Diabetesand Metabolism, vol. 18, no. 3, pp. 89-95, 2012.

[16] M. Numasaki, J.-I. Fukushi, M. Ono et al., "Interleukin-17 promotes angiogenesis and tumor growth," Blood, vol. 101, no. 7, pp. 2620-2627, 2003.

[17] T. Danne, O. Kordonouri, I. Enders, G. Hövener, and B. Weber, "Factors modifying the effect of hyperglycemia on the development of retinopathy in adolescents with diabetes. Results of the Berlin Retinopathy Study," Hormone Research, vol. 50, no. 1, pp. 28-32, 1998. 
[18] "Fundus photographic risk factors for progression of diabetic retinopathy. ETDRS report number 12: early Treatment Diabetic Retinopathy Study Research Group," Ophthalmology, vol. 98, supplement 5, pp. 823-833, 1991.

[19] D. R. Matthews, I. M. Stratton, S. J. Aldington, R. R. Holman, and E. M. Kohner, "Risks of progression of retinopathy and vision loss related to tight blood pressure control in type 2 diabetes mellitus: UKPDS 69," Archives of Ophthalmology, vol. 122, no. 11, pp. 1631-1640, 2004.

[20] N. Younis, D. M. Broadbent, S. P. Harding, and J. P. Vora, "Prevalence of diabetic eye disease in patients entering a systematic primary care-based eye screening programme," Diabetic Medicine, vol. 19, no. 12, pp. 1014-1021, 2002.

[21] K. E. Mortlock, Z. Chiti, N. Drasdo, D. R. Owens, and R. V. North, "Silent substitution S-cone electroretinogram in subjects with diabetes mellitus," Ophthalmic and Physiological Optics, vol. 25, no. 5, pp. 392-399, 2005.

[22] Z. Chiti, R. V. North, K. E. Mortlock, and N. Drasdo, "The Scone electroretinogram: a comparison of techniques, normative data and age-related variation," Ophthalmic and Physiological Optics, vol. 23, no. 4, pp. 370-376, 2003.

[23] M. F. Marmor, L. Cabael, S. Shukla, J. C. Hwang, and M. Marcus, "Clinical S-cone ERG recording with a commercial hand-held full-field stimulator," Documenta Ophthalmologica, vol. 109, no. 1, pp. 101-107, 2004.

[24] D. R. Lucas and J. P. Newhouse, "The toxic effect of sodium Lglutamate on the inner layers of the retina," A.M.A. Archives of Ophthalmology, vol. 58, no. 2, pp. 193-201, 1957.

[25] D. A. Antonetti, A. J. Barber, S. K. Bronson et al., "Diabetic retinopathy: seeing beyond glucose-induced microvascular disease," Diabetes, vol. 55, no. 9, pp. 2401-2411, 2006.

[26] S. Caputo, M. A. S. Di Leo, B. Falsini et al., "Evidence for early impairment of macular function with pattern ERG in type I diabetic patients," Diabetes Care, vol. 13, no. 4, pp. 412-418, 1990.

[27] G. Ghirlanda, M. A. S. Di Leo, S. Caputo et al., "Detection of inner retina dysfunction by steady-state focal electroretinogram pattern and flicker in early IDDM," Diabetes, vol. 40, no. 9, pp. 1122-1127, 1991.

[28] T. C. Prager, C. A. Garcia, C. A. Mincher, J. Mishra, and H.-H. $\mathrm{Chu}$, "The pattern electroretinogram in diabetes," The American Journal of Ophthalmology, vol. 109, no. 3, pp. 279-284, 1990.

[29] G. L. Trick, R. M. Burde, M. O. Gordon, C. Kilo, and J. V. Santiago, "Retinocortical conduction time in diabetics with abnormal pattern reversal electroretinograms and visual evoked potentials," Documenta Ophthalmologica, vol. 70, no. 1, pp. 1928, 1988.

[30] B. Falsini, V. Porciatti, G. Scalia et al., "Steady-state pattern electroretinogram in insulin-dependent diabetics with no or minimal retinopathy," Documenta Ophthalmologica, vol. 73, no. 2, pp. 193-200, 1989.

[31] A. V. Greco, M. A. S. Di Leo, S. Caputo et al., "Early selective neuroretinal disorder in prepubertal type 1 (insulin-dependent) diabetic children without microvascular abnormalities," Acta Diabetologica, vol. 31, no. 2, pp. 98-102, 1994.

[32] J. Siebert and M. Reiwer-Gostomska, "The role of angiogenic growth factors in the development of diabetic complications," Kardiologia Polska, vol. 67, no. 1, pp. 62-64, 2009.

[33] A. Araszkiewicz, D. Zozulioska, and B. Wierusz-Wysocka, "Assessment of vascular-endothelial growth factor(VEGF) serum concentrationin typel diabetic subjects," Diabetologia Doświadczalna i Kliniczna, vol. 4, supplement 3, pp. 197-201, 2004.
[34] J. Cai and M. Boulton, "The pathogenesis of diabetic retinopathy: old concepts and new questions," Eye, vol. 16, no. 3, pp. 242260, 2002.

[35] D. Shweiki, A. Itin, D. Soffer, and E. Keshet, "Vascular endothelial growth factor induced by hypoxia may mediate hypoxiainitiated angiogenesis," Nature, vol. 359, no. 6398, pp. 843-845, 1992.

[36] L. P. Aiello, J. M. Northrup, B. A. Keyt, H. Takagi, and M. A. Iwamoto, "Hypoxic regulation of vascular endothelial growth factor in retinal cells," Archives of Ophthalmology, vol. 113, no. 12, pp. 1538-1544, 1995.

[37] A. W. Stitt, C. McGoldrick, A. Rice-McCaldin et al., "Impaired retinal angiogenesis in diabetes: role of advanced glycation end products and galectin-3," Diabetes, vol. 54, no. 3, pp. 785-794, 2005.

[38] R. Simó and C. Hernández, "Intravitreous anti-VEGF for diabetic retinopathy: hopes and fears for a new therapeutic strategy," Diabetologia, vol. 51, no. 9, pp. 1574-1580, 2008.

[39] P. L. Lip, F. Belgore, A. D. Blann, M. W. Hope-Ross, J. M. Gibson, and G. Y. H. Lip, "Plasma VEGF and soluble VEGF receptor FLT-1 in proliferative retinopathy: relationship to endothelial dysfunction and laser treatment," Investigative Ophthalmology and Visual Science, vol. 41, no. 8, pp. 2115-2119, 2000.

[40] F. Santilli, A. Spagnoli, A. Mohn et al., "Increased vascular endothelial growth factor serum concentrations may help to identify patients with onset of type 1 diabetes during childhood at risk for developing persistent microalbuminuria," The Journal of Clinical Endocrinology and Metabolism, vol. 86, no. 8, pp. 3871-3876, 2001.

[41] R. H. Amin, R. N. Frank, A. Kennedy, D. Eliott, J. E. Puklin, and G. W. Abrams, "Vascular endothelial growth factor is present in glial cells of the retina and optic nerve of human subjects with nonproliferative diabetic retinopathy," Investigative Ophthalmology and Visual Science, vol. 38, no. 1, pp. 36-47, 1997.

[42] G. A. Lutty, D. S. McLeod, C. Merges, A. Diggs, and J. Plouét, "Localization of vascular endothelial growth factor in human retina and choroid," Archives of Ophthalmology, vol. 114, no. 8, pp. 971-977, 1996.

[43] H. Er, S. Doğanay, E. Özerol, and M. Yürekli, "Adrenomedullin and leptin levels in diabetic retinopathy and retinal diseases," Ophthalmologica, vol. 219, no. 2, pp. 107-111, 2005.

[44] S. C. Lim, N. G. Morgenthaler, T. Subramaniam, Y. S. Wu, S. K. Goh, and C. F. Sum, "The relationship between adrenomedullin, metabolic factors, and vascular function in individuals with type 2 diabetes," Diabetes Care, vol. 30, no. 6, pp. 1513-1519, 2007.

[45] T. Udono, K. Takahashi, S. Takano, S. Shibahara, and M. Tamai, "Elevated adrenomedullin in the vitreous of patients with proliferative vitreoretinopathy," The American Journal of Ophthalmology, vol. 128, no. 6, pp. 765-767, 1999.

[46] T. Nishikimi, K. Kitamura, Y. Saito et al., "Clinical studies on the sites of production and clearance of circulating adrenomedullin in human subjects," Hypertension, vol. 24, no. 5, pp. 600-604, 1994.

[47] T. Ishimitsu, T. Nishikimi, Y. Saito et al., "Plasma levels of adrenomedullin, a newly identified hypotensive peptide, in patients with hypertension and renal failure," The Journal of Clinical Investigation, vol. 94, no. 5, pp. 2158-2161, 1994.

[48] M. T. García-Unzueta, C. Montalbán, C. Pesquera, J. R. Berrazueta, and J. A. Amado, "Plasma adrenomedullin levels in type 1 diabetes: relationship with clinical parameters," Diabetes Care, vol. 21, no. 6, pp. 999-1003, 1998. 
[49] F. A. Zakareia, A. A. Alderees, K. A. Al Regaiy, and F. A. Alrouq, "Correlation of electroretinography b-wave absolute latency, plasma levels of human basic fibroblast growth factor, vascular endothelial growth factor, soluble fatty acid synthase, and adrenomedullin in diabetic retinopathy," Journal of Diabetes and Its Complications, vol. 24, no. 3, pp. 179-185, 2010.

[50] T. Taniguchi, K. Kawase, Z.-B. Gu et al., "Ocular effects of adrenomedullin," Experimental Eye Research, vol. 69, no. 5, pp. 467-474, 1999.

[51] T. Udono, K. Takahashi, M. Nakayama et al., "Induction of adrenomedullin by hypoxia in cultured retinal pigment epithelial cells," Investigative Ophthalmology and Visual Science, vol. 42, no. 5, pp. 1080-1086, 2001.

[52] T. Okamura, K. Ayajiki, K. Kangawa, and N. Toda, "Mechanism of adrenomedullin-induced relaxation in isolated canine retinal arteries," Investigative Ophthalmology and Visual Science, vol. 38, no. 1, pp. 56-61, 1997.

[53] J. Honkanen, J. K. Nieminen, R. Gao et al., "IL-17 immunity in human type 1 diabetes," Journal of Immunology, vol. 185, no. 3, pp. 1959-1967, 2010.

[54] A. K. Marwaha, S. Q. Crome, C. Panagiotopoulos et al., "Cutting edge: increased IL-17-secreting T cells in children with newonset type 1 diabetes," Journal of Immunology, vol. 185, no. 7, pp. 3814-3818, 2010.

[55] R. Piekarski and L. Szewczyk, "The role of Th17 cells in type 1 diabetes," Endokrynologia Pediatryczna, vol. 4, no. 37, pp. 61-68, 2011. 


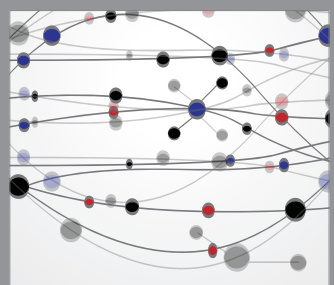

The Scientific World Journal
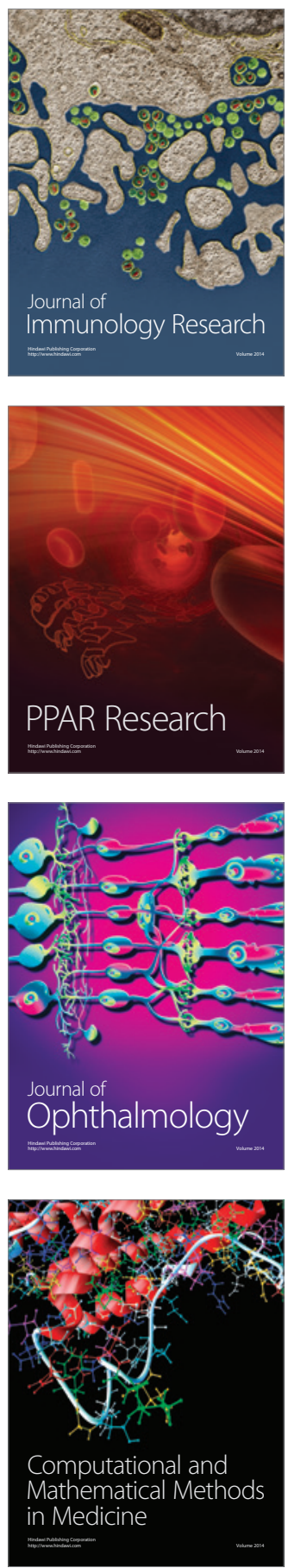

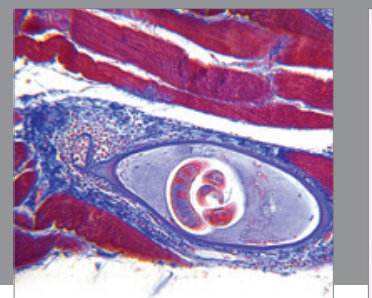

Gastroenterology

Research and Practice
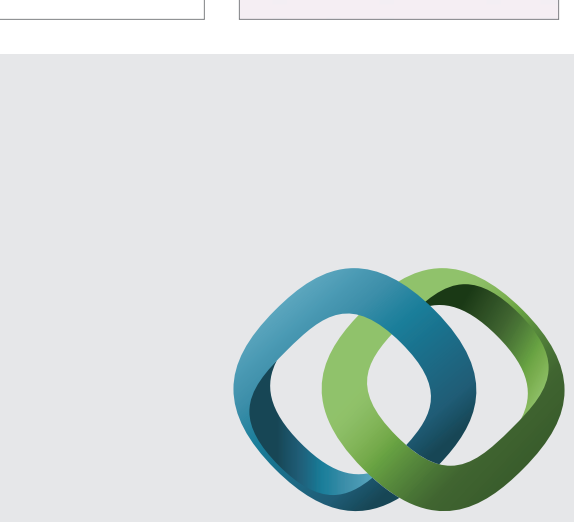

\section{Hindawi}

Submit your manuscripts at

http://www.hindawi.com
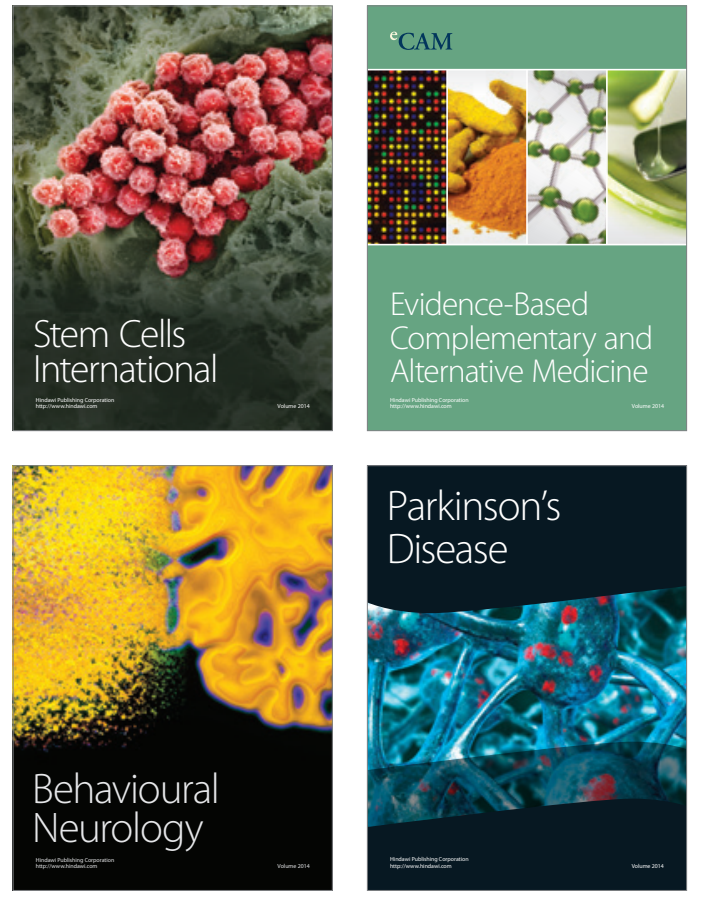
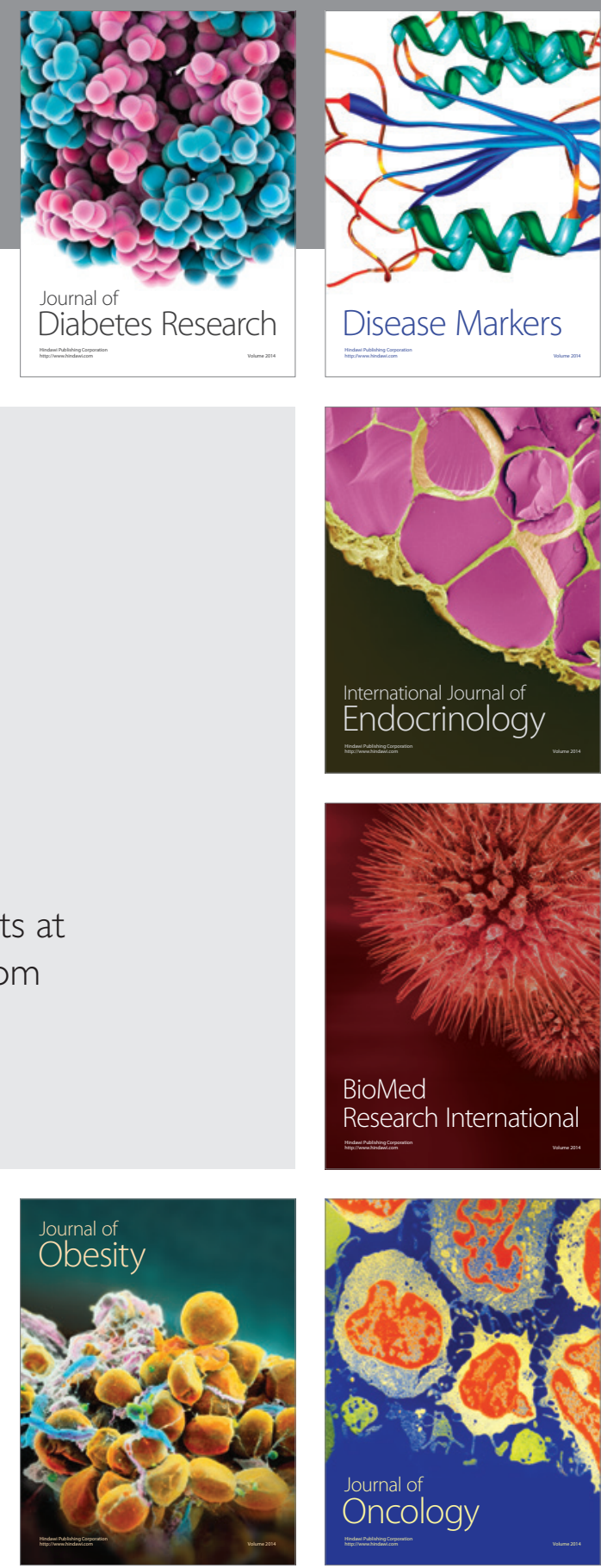

Disease Markers
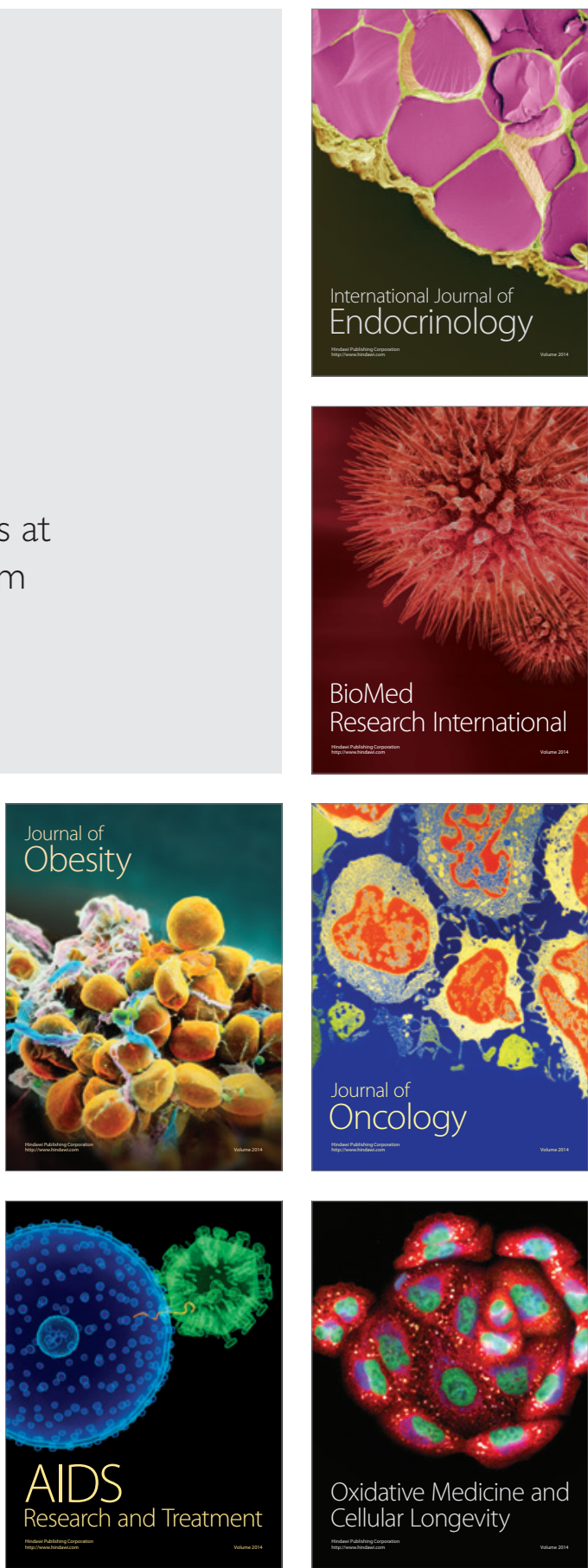